\title{
A POLITICA DE EDUCAÇÃO NO PERIODO POPULISTA - DESENVOLVIMENTISTA (1945 - 1964)
}

\author{
Aline Linares de Oliveira Scandelai ${ }^{1}$ \\ ${ }^{1}$ Graduada em Serviço Social e Especialista em Políticas Sociais e Processos de gestão, pelas Faculdades Integradas Antonio \\ Eufrásio de Toledo de Presidente Prudente/SP. Especialista em Democracia Participativa, República e Movimentos Sociais pela \\ Universidade Federal de Minas Gerais. aline.linares@hotmail.com.
}

\section{RESUMO}

O presente artigo analisa a postura e a importância da Educação na gestão dos Presidentes da República que governaram o Brasil durante os anos de 1945 a 1964, período esse denominado pela história de "populista - desenvolvimentista"; Ressalta as conquistas, como a efetivação da primeira Lei de Diretrizes e Bases da Educação e, os desapontamentos, com quase metade de uma década sem nenhum investimento no sistema educacional. Nos quatro anos iniciais do novo mandato de Getúlio Vargas são mantidos o populismo, o desenvolvimento da indústria, do petróleo, há incentivo ao trabalho, educação e assistência. Uma crítica deve ser feita: não há durante o presente governo atenção ao trabalhador rural. A gestão de Juscelino Kubitschek tem como principal atrativo o capital externo. Há incentivo para o Nordeste e a construção da capital do Brasil: Brasília. Um aspecto desfavorável a esse governo é a neutralização de políticas sociais. As gestões de Jânio Quadros e João Goulart têm bases solidificadas no socialismo. Há uma estagnação econômica na época e inflação acentuada, porém apresentam incentivos ao trabalho, à educação e à Previdência Social. O aspecto negativo é a não atenção aos trabalhadores rural e doméstico. Palavras-chave: Educação; Trabalho; Saúde; Previdência Social; Desenvolvimentista.

\section{THE POLITIC OF EDUCATION IN PERIOD POPULIST - DEVELOPMENTALIST}

\begin{abstract}
This article examines the posture and the importance of education in the management of Presidents of the Republic to govern Brazil for the years1945 to 1964, a period in history called "populist-development", highlighted the achievements, as the realization the first Law of Directives and Bases of Education, and disappointments, as almost half a decade without any investment in the education system. The four initial years of the new term of Vargas are kept populism, the development of industry, petroleum; there is incentive to work, education and assistance. A complaint must be made: there is no attention to rural workers during the present government. The management of Juscelino Kubitschek main attraction foreign capital. There is an incentive for the Northeast and the construction of Brazil capital: Brasilia. An unfavorable aspect to this government is the neutralization of social policies. The managements of Quadros and Goulart bases have solidified into socialism. There is an economic stagnation and inflation at the time marked, but they have incentives to work, education and Social Security. The downside is no attention to rural and domestic workers.
\end{abstract}

Keywords: Education; Labor; Health; Welfare; Developmental. 


\section{INTRODUÇÃO}

Com base em bibliografias das últimas três décadas e sites com conteúdo de fonte segura é possível apresentar prévio contexto da Política de Educação durante meados da década de quarenta ao início da década de sessenta.

Com o objetivo de descrever brevemente a evolução e retrocesso da Política de Educação no período "populista e desenvolvimentista" (registrado entre os anos de 1945 a 1964), a presente pesquisa bibliográfica apresenta 0 resultado do trabalho das gestões presidencialistas. Esclarece que ações efetivas de cada presidente se concretizam não somente pela figura do Presidente, mas por todos os que compõem a gestão.

A história registra a gestão do governo de Getúlio Vargas em dois momentos: o primeiro durante os anos de 1930 a 1945 e, o último de 1950 a 1954.

Quando encerrada a segunda gestão do Presidente Vargas, o Brasil vivencia uma série de mudanças estruturais que ganham velocidade a partir da década de trinta, que diz respeito principalmente às bases do desenvolvimento do modelo econômico adotado, à ênfase na industrialização orientada pelo Estado, à liberalização política e ao controle social e sindical.

Entre os anos de 1945 e 1964, duas propostas ocupam o centro da discussão sobre o modelo de desenvolvimento econômico mais apropriado ao Brasil, com o objetivo de combater às já seculares mazelas sociais.

As duas propostas, entretanto, possuem alguns pontos em comum, a exemplo da importância que devem ser atribuída ao processo de industrialização, como base do desenvolvimentismo sócio-econômico. Dentre os pontos divergentes, há duas visões de mundo ou, de projeto de sociedade: uma defende maior ênfase ao aspecto nacionalista e a outra, apoia a ampla abertura ao capital estrangeiro. O embate entre essas duas propostas de modelo econômico para o país resulta na adoção de políticas públicas em determinado período da nossa história.

A primeira fase deste período é no governo de Getúlio Vargas (1951-1954), em que predomina a implantação de um modelo de medidas de cunho nacionalista, que tem seu auge na campanha O Petróleo é Nosso e culmina na criação da Petrobrás. A segunda fase, já no governo Juscelino Kubtischek (1956-1961), é o marco de um conjunto de medidas, cuja meta 50 anos em 5 - é o crescimento econômico do país associado ao capital estrangeiro em detrimento de uma política de estabilidade monetária, o que possibilita a entrada de empresas estrangeiras, principalmente no setor automotivo. Neste cenário, a indústria de base no Brasil é um dos setores que recebe maior recurso, ao lado dos ramos de energia e de transportes.

A gestão do governo de João Goulart tem uma ação rápida que evidencia o estilo político de um ministro que gosta de falar pessoalmente com lideranças sindicais e que intervêm diretamente na dinâmica das negociações dos conflitos trabalhistas. De fato, esse é o tom que marca a sua curta e ativa gestão na pasta do Trabalho: maior aproximação com setores sindicais.

\section{1 - A EDUCAÇÃO NA ERA DESENVOLVIMENTISTA}

É contrastante falar sobre educação no período em que a história do país se denomina desenvolvimentista. A primeira idéia transmitida é que o momento da história com tal titulação evolui/desenvolve - como a própria palavra se deriva - em todos os segmentos. Infelizmente denota um grande lapso se analisada, por exemplo, a educação, tendo em vista que o sistema educacional do país caminha nesse 
período a passos estreitos, em alguns momentos retrocede no que já foi alcançado.

A educação foi colocada
em segundo plano na
política brasileira. Poucos
pensaram em melhorar o
nível de escolaridade ou
acabar com or o
analfabetismo. No Censo
de 1940, foram registrados
$56,17 \%$ de analfabetos
entre a população com
idade superior a 15 anos.
Mais tarde, na Constituição
de 1946, ficou prevista a
elaboração da Lei de
Diretrizes e Bases da
Educação Nacional (LDB),
em virtude da pressão de
um grupo de intelectuais
que, no ano de 1932,
iniciou o Manifesto da
Escola Nova (ou Manifesto
dos Pioneiros da Educação
Nova), que atribuía ao
Estado o dever de garantir
ao povo escola pública,
obrigatória, gratuita e
desvinculada da Igreja ${ }^{1}$.

$\mathrm{Na}$ educação, sob a perspectiva das quatro gestões administrativas do Brasil, entre os anos de 1954 a 1964, é possível analisar diferentes focos nos governos: a educação não é prioridade em nenhum deles, os projetos públicos sempre focalizam o concreto, o imediato, ou seja, planos em curto e médio prazo e, que são materializados, como exemplo, a construção de Brasília por Juscelino Kubitschek.

Com base nas ações evidenciadas pelos presidentes, é verificada a educação como um âmbito que não recebe atenção ou recursos, na qual se fazem necessários, e ressalta que as conquistas ocorrem devido às pressões da sociedade civil organizada, principalmente por meio de conferências, levantamento de bandeiras, manifestações, revoluções, que marcam a luta pelos interesses da sociedade.

\footnotetext{
${ }^{1}$ Fonte:

http://www.educacional.com.br/noticiacomentada/060227not01 .asp - Acesso em 30 de Maio de 2011.
}

A democracia é includente, acolhe todos os interesses. Para ela a paz não é a ausência de conflitos, é o resultado de uma sociedade capaz de aceitar regras para diminuir 0 conflito sem eliminar 0 outro (nem física, nem sociológica, nem psicologicamente). $\quad \mathrm{Na}$ democracia, não existem os inimigos, mas opositores: pessoas que pensam diferente "querem diferente" e têm interesses diferentes, que podem colidir com os dos outros, mas com os quais é possível conciliar futuros comuns. (TORO, 2005, p.28).

\section{2 - CAFÉ FILHO: O REFLEXO DO SISTEMA EDUCACIONAL DE GETÚLIO}

O Presidente que sucede Getúlio Vargas após sua morte, Café Filho, governa o país por quase dois anos (1954 a 1956). Suas ações públicas resultam na penetração do capital estrangeiro e no descontentamento da classe operária e dos nacionalistas.

No âmbito educacional, no ano de 1954 é fundada no Estado do Ceará uma Universidade Federal. Já o Ministério da Educação desse período efetiva alguns programas e campanhas sobre a responsabilidade do ministro, Cândido Mota Filho. Alguns deles foram:

- a fundação do Instituto Superior de Estudos Brasileiros - ISEB - que visa criar uma cultura brasileira;

- a Campanha Nacional de Alimentação Escolar CNAE;

- juntamente com Anísio Teixeira², são fundados Centros de Pesquisa Educacionais, nos municípios de São Paulo, Rio de Janeiro, Recife, Belo Horizonte, Salvador e Porto Alegre.

\footnotetext{
${ }^{2}$ Graduado em Ciências Jurídicas e Sociais, foi secretário de Educação do Rio de Janeiro; conselheiro da Organização das Nações Unidas para Educação (Unesco); diretor do Instituto Nacional de Estudos Pedagógicos (Inep) etc.
} 
E no âmbito da educação privada, são fundadas no município de Campinas e no Estado da Paraíba, a Pontifícia Universidade Católica PUC.

\section{3 - JUSCELINO KUBITSCHEK: O FURACÃO}

Juscelino Kubitschek, presidente que governa o Brasil no período de 31 de janeiro de 1956 a 30 de Janeiro de 1961, se torna popular e imortalizado na história da política do país com a concretização da construção de Brasília.

O ano de 1956 significa otimização para distintos setores do país, "alimentação, siderurgia, saneamento básico, eletrodomésticos, naval e nuclear (...) a abertura de estradas, a eletrificação, a implantação de um parque automobilístico" (AMARAL, 2006, p.104).

A efetivação do projeto da construção Brasília e, de transferir a capital do Brasil para o interior, ou seja, para o centro do país, mobiliza toda a estrutura física, humana e econômica presente na atual gestão política.

Juscelino Kubitschek é registrado pela história do Brasil, como furacão e o artista do impossível $^{3}$. Como furacão arrasta a capital do país por quilômetros, faz girar - e em grande velocidade - o setor automobilístico. E como uma das características do furacão é a destruição que realiza por onde passa, JK não fez diferente, também causa destruições, começando com a economia do país - com o aumento da dívida externa - e com a ausência de políticas sociais e educacionais.

A concepção desenvolvimentista de JK não consagrou a educação, que recebeu apenas 3\% da verba para investimentos no país. Além disso, esse dinheiro foi direcionado principalmente à educação técnica (considerada como base para o crescimento industrial). Nada foi feito

${ }^{3}$ Titulo dado ao livro de JK: O artista do impossível com autoria de Cláudio Bojunga. com relação à educação básica ${ }^{4}$.

Durante o governo de JK, a sociedade civil organiza Conferências Nacionais, na busca pela viabilização da educação, ou seja, um sistema educacional que esteja ao alcance de toda a população.

É nos meados da década de 50 , mais precisamente em 1955, que emerge um dos maiores educadores do Brasil, Paulo Freire, que havia terminado uma pesquisa realizada no Serviço Social da Indústria - SESI - no período de 1946 a 1955, onde visa estudar as relações entre alunos, mestres e pais de alunos. $O$ resultado de tal pesquisa é útil para sua tese ${ }^{5}$ publicada no ano de 1959 e, para reflexão da situação do sistema educacional no país.

O Ministério da Educação cria no ano de 1957 a Campanha de Aperfeiçoamento e Difusão do Ensino Secundário - CADES, que resulta na criação da Revista Escola Secundária. E no mesmo ano é fundada a Universidade Federal do Pará.

Em 1958, há registros do Censo Nacional que metade da população do país é analfabeta. A partir desses índices são realizadas a Campanha Nacional de Erradicação do Analfabetismo CNEA, o II Congresso Nacional de Educação de Adultos e é fundada a Universidade Federal do Rio Grande do Norte.

No ano de 1959, o Jornal O Estado de São Paulo, juntamente com os educadores progressistas, desencadearam a Campanha de Defesa da Escola Pública, um manifesto que buscava desenvolver o sistema educacional no país. Ressalta que, enquanto avança o capitalismo industrial, a educação continua estruturada em bases, valores e técnicas do pré-

\footnotetext{
$4 \quad$ Fonte:

http://www.educacional.com.br/noticiacomentada/060227not01 .asp - Acesso em 30 de Maio de 2011.

${ }^{5}$ Tese de concurso para a cadeira de História e Filosofia da educação na escola de Belas Artes de Pernambuco. Recife, 1959.
} 
capitalista. Nesse ano, centenas de educadores se organizam para manifestar contra a efetivação da Lei de Diretrizes e Bases da Educação Nacional, visto que só no período governado por Juscelino, foram propostos dois textos distintos sobre o sistema educacional e nenhum deles foi efetivado.

Por isso, no ano de 1959, foi retomada a discussão por parte dos "escolanovistas", desta vez fortalecida com a presença de Darci Ribeiro e Fernando Henrique Cardoso. Apesar do baixo investimento na educação, o Censo de 1960 indicou uma diminuição no número de analfabetos com mais de 15 anos $(39,35 \%)^{6}$.

O ano de 1960 representa um avanço no ensino superior, tanto público como privado. São fundadas:

- Pontifícia Universidade Católica de Pelotas;

- Universidade Federal Fluminense;

- Universidade Federal de Goiás;

- Universidade Federal de Juiz de Fora;

- Universidade Federal de Santa Catarina;

- Universidade Federal de Santa Maria.

Esses avanços resultam na organização da União Nacional dos Estudantes - UNE, que tem como a base no ideário da Reforma Universitária.

\section{4 - JÂNIO QUADROS: A EDUCAÇÃO EM BRANCO}

Candidato que vence as eleições em 1961, Jânio Quadros fica à frente da presidência apenas por oito meses. Nesse período não há registros de ações realizadas no âmbito educacional, apenas é evidenciada uma política econômica deficitária. Quando renunciou em agosto de 1961, esperava a aclamação e apoio

\footnotetext{
${ }^{6}$ Fonte:

http://www.educacional.com.br/noticiacomentada/060227not01 .asp - Acesso em 30 de Maio de 2011.
}

do exército e da burguesia, mas esse fato não ocorreu.

\section{5 - JOÃO GOULART: A EDUCAÇÃO AVANÇA E INICIA A DITADURA}

Um governante que assume a presidência do Brasil, após a renuncia de Jânio Quadros, seu vice, João Goulart, se apóia nos trabalhadores, sugerindo reformas de base com intuito da redução dos abismos sociais do Brasil. Com aprovação de $47 \%$ dos entrevistados em pesquisa nacional, João Goulart, governa durante o período de 7 de setembro de 1961 ao final do ano de 1965. E para a educação é uma gestão que apresenta ações com resultados mais expressivos.

O final do ano de 1961 significa um marco para o âmbito educacional e uma conquista para aqueles que desde a Constituição Federal de 1934 lutam pela efetivação de uma política especifica que trata dos assuntos inerentes ao sistema educacional. A Lei de Diretrizes e Bases da Educação - LDB -, emerge em resposta a esse segmento da sociedade. Treze anos após ser encaminhado o primeiro projeto de lei pelo Poder Executivo ao Legislativo - 1948 - onde visa a definição e regularização do sistema de educação brasileira.

Mais de uma década no aguardo da efetivação da LDB se dá pelas brigas políticas entre os estatistas - com postura esquerdista, partiam do principio que a finalidade da educação é prepar o indivíduo para a sociedade e que só o Estado deve cuidar desse âmbito - com os liberalistas - lidados a partidos de direita, defendiam que,

a pessoa possui direitos naturais e que não cabe ao Estado garanti-los ou negálos, mas simplesmente respeitá-los. A educação é um dever da família que deve escolher dentre uma variedade de opções de escolas particulares. Ao 
Estado caberia a função de traçar as diretrizes do sistema educacional e garantir por intermédio de bolsas o acesso às escolas particulares para as pessoas de famílias de baixa renda"7.

As principais caracteristicas estabelecidas pela Lei de Diretrizes e Bases são:

[...] uma maior autonomia aos órgãos estaduais, diminuindo a centralização do poder no MEC; regulamenta a existência dos Conselhos Estaduais de Educação e do Conselho Federal de Educação; garante o empenho de $12 \%$ do orçamento da União e $20 \%$ dos municípios com a educação; dinheiro público não exclusivo às instituições de ensino públicas; obrigatoriedade de matrícula nos quatro anos do ensino primário; formação do professor para o ensino primário no ensino normal de grau ginasial ou colegial; formação do professor para o ensino médio nos cursos de nível superior; ano letivo de 180 dias; ensino religioso facultativo $^{8}$.

Ressalta que, apesar de todos os princípios, a Lei de Diretrizes e Bases da Educação permite abertura para a expansão de escolas e universidades por iniciativa privada e, para a educação popular garante modestas reformas de organização e conteúdo.

[...] com a Lei de Diretrizes
e Bases da Educação
Nacional, promulgou-se
uma série de leis, decretos
e portarias ministeriais,

http://pt.wikipedia.org/wiki/Lei de Diretrizes e Bases da Edu ca\%C3\%A7\%C3\%A30 - Acesso em 02 de Maio de 2007.

http://pt.wikipedia.org/wiki/Lei de Diretrizes e B ases da Educa\%C3\%A7\%C3\%A30 - Acesso em 02 de Maio de 2007. cada uma delas dando um passo à frente na unificação dos segmentos do sistema educacional. É preciso destacar que essa legislação não corresponde a uma política do Estado previamente formulada, mas foi sendo elaborada na medida da pressão da clientela interessada. (CUNHA, 1980, p. 238).

Nesse período, os estudantes universitários, através da União Nacional dos Estudantes - UNE, se organizam em manifestações que sacodem zonas urbanas e rurais. Erguem bandeiras, reivindicam uma reforma universitária, onde se visa uma nova proposição pedagógica, a democratização do ensino, ou seja, a luta por um espaço educacional onde sejam incluídos os negros, os pobres e os indivíduos residentes nas zonas rurais.

Ainda no mesmo período há a Conferência Nacional dos Bispos do Brasil CNBB - que está diretamente vinculada ao movimento que luta por uma Educação de Bases. Esse evento apresenta por missão

[...] a promoção integral, humana e cristã de jovens e adultos, desenvolvendo programas de educação popular na perspectiva de formação e qualificação das camadas populares e promoção da cidadania, buscando trilhar os caminhos de superação de perversos mecanismos de exclusão social ${ }^{9}$

Ainda no ano de 1961, inicia a campanha para erradicar ou pelo menos diminuir os índices de analfabetismo do país, tendo em vista que há registros que metade da população brasileira é analfabeta. Sob a supervisão de Paulo Freire, a campanha de alfabetização De pé no chão

\footnotetext{
9 http://momidi.com.br/meb - Acesso em 02 de Maio de 2007.
} 
também se aprende a ler, tem como técnica didática alfabetizar adultos em 40 horas. Mas a campanha não ocorre em âmbito nacional; devido à ausência de incentivos, fica restringida aos Estados do Rio Grande do Norte e Pernambuco.

No ano posterior - 1962 - é efetivado, através do Ministério da Educação, o Programa Nacional de Alfabetização, inspirado no Método Paulo Freire e na campanha realizada em Cuba onde, em um ano, consegue erradicar 0 analfabetismo no país - surge em resposta aos altos índices de analfabetismo e principalmente para que o Estado demonstrasse à população preocupação com a situação da educação. Na realidade, pode-se verificar que nesse mesmo período emerge nos meios de produção da indústria do país o modelo fordista, que necessita de mão de obra qualificada, ou seja, de trabalhadores que pelo menos saibam ler as instruções de como utilizar o maquinário e é nesse fato que se verifica o motivo do Estado estar focado na erradicação do analfabetismo, tendo em vista que com trabalhadores analfabetos, a produção industrial do país irá à falência.

[...] O Ministério da
Educação e Cultura
estimava que cinqüenta por
cento a percentagem de
alfabetos na população
adulta do país. Entendido,
aliás, no Ministério, como
alarmante expressão de um
grave problema da
educação brasileira, esse
indicador vinha mesmo
justificando a instituição de
um projeto de amplas
proporções, a Campanha
Nacional de Erradicação do
Analfabetismo. Entre as
evidências da importância
então atribuídas pelo
Ministério à questão do
analfabetismo, incluía-se,
também em 1958, a
promoção do II Congresso
Nacional de Educação de
Adultos, dedicado à análise
e a revisão crítica dos

programas em desenvolvimento neste setor do ensino [...]. Mas o episódio ainda não configurava um envolvimento maior do professor com o fenômeno específico do analfabetismo entre adultos. (BEISIEGEL, 1992, p.109).

No mesmo ano, são criados o Conselho Federal de Educação, o Conselho Estadual de Educação e o Plano Nacional de Educação, sendo cumprido o que propõe a LDB. A efetivação de tais órgãos se dá tendo em vista que a gestão política tem que provar aos manifestantes e aos líderes educacionais que está fazendo cumprir-se a Lei. Por um outro prisma, os órgãos são criados e isso não significa que eles realmente cumprem suas funções assim como a lei expressa. A efetivação dos Conselhos voltados para a educação é como uma resposta, o cala boca ${ }^{10}$ para os revolucionários.

Em 1964, graças a recursos provenientes das empresas privadas, a Lei de n. ${ }^{04} 440$ institui um salário-educação, como incentivo à matricula e a frequência na escola pelas famílias menos abastadas.

Nos últimos três anos do governo de João Goulart são fundadas a Universidade de Brasília, a Universidade Federal de Alagoas e a do Espírito Santo, a Universidade Católica de Petrópolis e a de Salvador, a Universidade Estadual de Campinas e a Universidade Norte de Ensino Superior de Montes Claros, Minas Gerais.

João Goulart, com uma gestão política de aspiração popular, faz com que nenhum âmbito fique desfalcado em seu governo.

[...] as bandeiras que o país levantava, como reivindicações dos trabalhadores da cidade e

\footnotetext{
${ }^{10}$ Gíria, quando utilizada no âmbito político é para expressar uma ação política para manter o povo quieto, ou seja, sem ações de manifestações ou revoluções.
} 
do campo, dos estudantes, dos intelectuais, dos sargentos, da vanguarda política, eram também as bandeiras de seu governo. (AFFONSO, 1997, p.15).

No âmbito da educação, os universitários conseguem colocar no ano de 1963, na Sessão Legislativa, a tão esperada reforma universitária, que visa integrar à constituição os seguintes princípios:

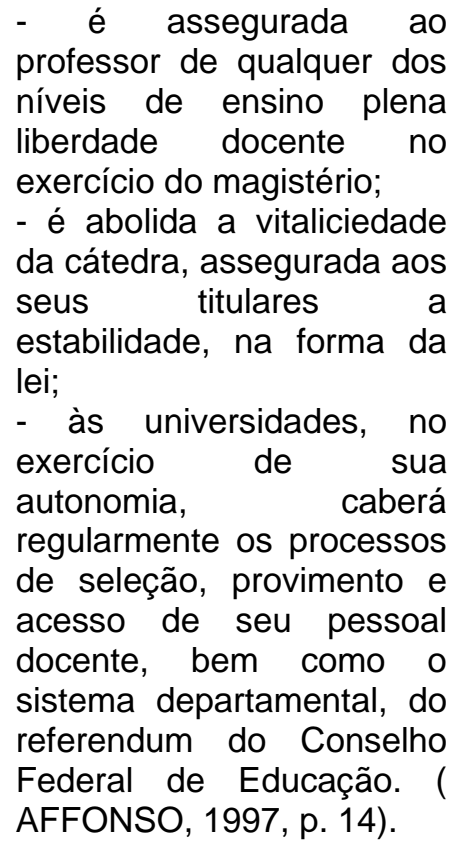

No ano seguinte a ditadura militar emerge no Brasil, ou seja, as lutas por reformas educacionais, por mudanças na legislação, para efetivação de diretrizes específicas à educação e, o Brasil não vivencia e usufrui das conquistas pelo menos não na década seguinte.

Quando emerge a ditadura militar o país é desmobilizado, a educação recebe fortes golpes, as universidades públicas são invadidas por tropas militares e muitos reitores são depostos de seus cargos. O lema da ditadura é estudante é para estudar; trabalhador para trabalhar. A partir de tal fato, a União Nacional dos Estudantes - UNE, é caracterizada como ilegal, e são substituídas por Diretórios Acadêmicos - DA's, restrito a cada curso, e o Diretório Central dos Estudantes - DCE, no âmbito da universidade. Essa ação elimina a representação a nível nacional, bem como qualquer tentativa de manifestação política.

E no mesmo ano, o então presidente João Goulart é deposto, visto que os militares o analisam como um representante do perigoso comunismo

\section{6 - A EDUCAÇÃO EM NÚMEROS}

A Constituição Federal de 1934 apresenta o preceito de educação é direito de todos, apesar das pesquisas apresentarem índices que distanciam a lei da realidade.

De acordo com censos, o final da década de 40 registra $^{11}$ a média que $56,1 \%$ da população no Brasil é analfabeta. Nos anos 50, são registrados índices de 50,7\%, visto que no final da década de 60 esses indicadores registram um avanço na educação, já que no momento fala-se em $39,6 \%$ dos brasileiros não saberem ler e escrever.

A diminuição do analfabetismo, como já citado, é reflexo do surgimento do fordismo ao país, devido à necessidade de instruir, educar a classe trabalhadora para trabalhar com a tecnologia - o uso das máquinas.

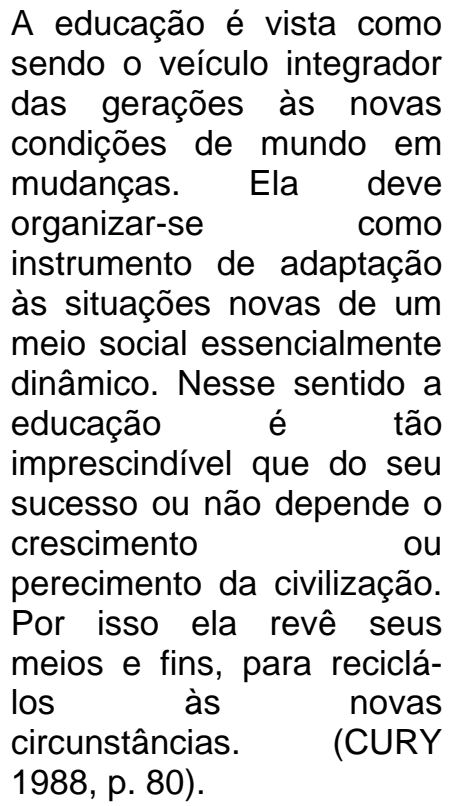

11

http://pt.wikipedia.org/wiki/Lei de Diretrizes e Bases da Edu ca\%C3\%A7\%C3\%A30 - Acesso em 02 de Maio de 2007. 
$\mathrm{Na}$ década de 50 , os números de matriculados nas escolas aumentam. No então denominado sistema primário, de 4.352.000 alunos aumentam para 7.141.000, um crescimento de mais de setenta por cento. No nível médio, o número de matriculados, que no início do ano de 1950 era de 540.000 alunos, no ano de 1960, são de 1.177.000. E o nível superior que no início da década registra apenas 49.700 alunos, ao final de dez anos é registrado 93.200 alunos.

Mas em uma outra perspectiva, segundo dados da Secretaria de Educação e Cultura e do Ministério de Educação e Cultura, de cada mil (1000) alunos matriculados na $1^{\underline{a}}$ série no ano de 1963, quatrocentos e quarenta e nove (449) passam para a $2^{\underline{a}}$ série, ou seja, em apenas um ano 55,1\% dos alunos evadem os estudos.

No ano de 1964 , pesquisas ${ }^{12}$ revelam que apenas $41,1 \%$ das crianças com sete anos de idade freqüentam a primeira série primária, sendo que dessas, 53,4\% residem nas zonas urbanas e 30,9\% nas zonas rurais. Essa diferença percentual de uma localidade para outra, enfatiza que as crianças pertencentes a zonas rurais têm menos acesso a educação devido ao número de escolas ser menor e principalmente, o trabalho na lavoura, que é visto como primordial e essencial para sobrevivência, ou seja, não sendo possível deixar de trabalhar para estudar.

Os altos índices de reprovas e evasão escolar fazem com que as crianças fiquem defasadas, não correspondendo a idade com a série. Tendo como base o levantamento de que apenas $41,1 \%$ das crianças se encontram nas escolas, dessas apenas 14,05\% estão com a idade correspondente para a série que estudam $^{13}$. Motivos para esses índices serem tão altos são muitos. A maior parte das crianças não são matriculadas nas escolas na idade recomendada - sete anos -, outras interrompem os estudos durante um período de tempo e anos mais tarde retornam.

No final do período aqui em estudo 1964 - há registros ${ }^{14}$ de que a taxa de escolarização na zona urbana atinge 79,6\% e na zona rural $49,7 \%$, ou seja, $64,2 \%$ da população do país passam pelos bancos das escolas, seja por um ou mais de dez anos de estudo.

Esses índices levam à reflexão de que o Estado pouco faz para incentivar a educação, ou a permanência das crianças na escola. As famílias que apresentam necessidade da mão-deobra dos filhos no trabalho têm como alternativa encaminhá-los no auxílio na lavoura - no caso daqueles que residem nas zonas rurais. Nas zonas urbanas, as crianças ficam em casa cuidam dos afazeres domésticos e dos irmãos mais jovens, enquanto os pais trabalham. Ressalta que o número de escolas desse período é baixo, muitas vezes a falta de estrutura física faz de uma única sala e um único professor ministra a aula para mais de uma série.

Diferente do que a Constituição Federal de 1946 e a Lei de Diretrizes e Bases de 1961 prevêem a educação no período de 1954 a 1964, a educação no Brasil se caracteriza e é confirmada através das estatísticas como um sistema fechado e excludente. Cunha, (1980, p.118), traz as seguintes características de um sistema educacional aberto:

- ao início de cada ano
letivo todas as crianças em
idade de ingresso na
escola são nela admitidas:
no caso brasileiro, todas as
crianças de sete anos de
idade ingressam na $1^{\text {a }}$ série
primária;
- ao fim de cada ano letivo,
todas as crianças
matriculadas

\footnotetext{
${ }^{12}$ Cunha, 1980. p. 121.
}

${ }^{13}$ Dados do ano de 1964.

${ }^{14}$ Cunha (1980, p. 137) 
aprovadas e promovidas à série seguinte;

- todas as crianças permanecem na escola até o final do curso; no nosso caso, todas as crianças concluem a $4^{\mathrm{a}}$ série com 10 anos de idade;

- não há evasão durante o ano letivo nem durante as férias escolares;

A proporção de crianças de 7 a 10 anos que freqüentam escola (taxa de escolarização) é de 100\%.
O sistema aberto que o autor cita é almejado por revolucionários educacionais da época, principalmente os que lutam por uma reforma de base. Mas se comparado com a contemporaneidade, pode se afirmar que somente meio século após a busca pela efetivação de um sistema educacional com tais características, a lei começa a ser efetivada, ressaltando que a taxa de escolarização da última década ainda não é de 100\%.

Taxa de analfabetismo, por grupos de idade ${ }^{15}$.

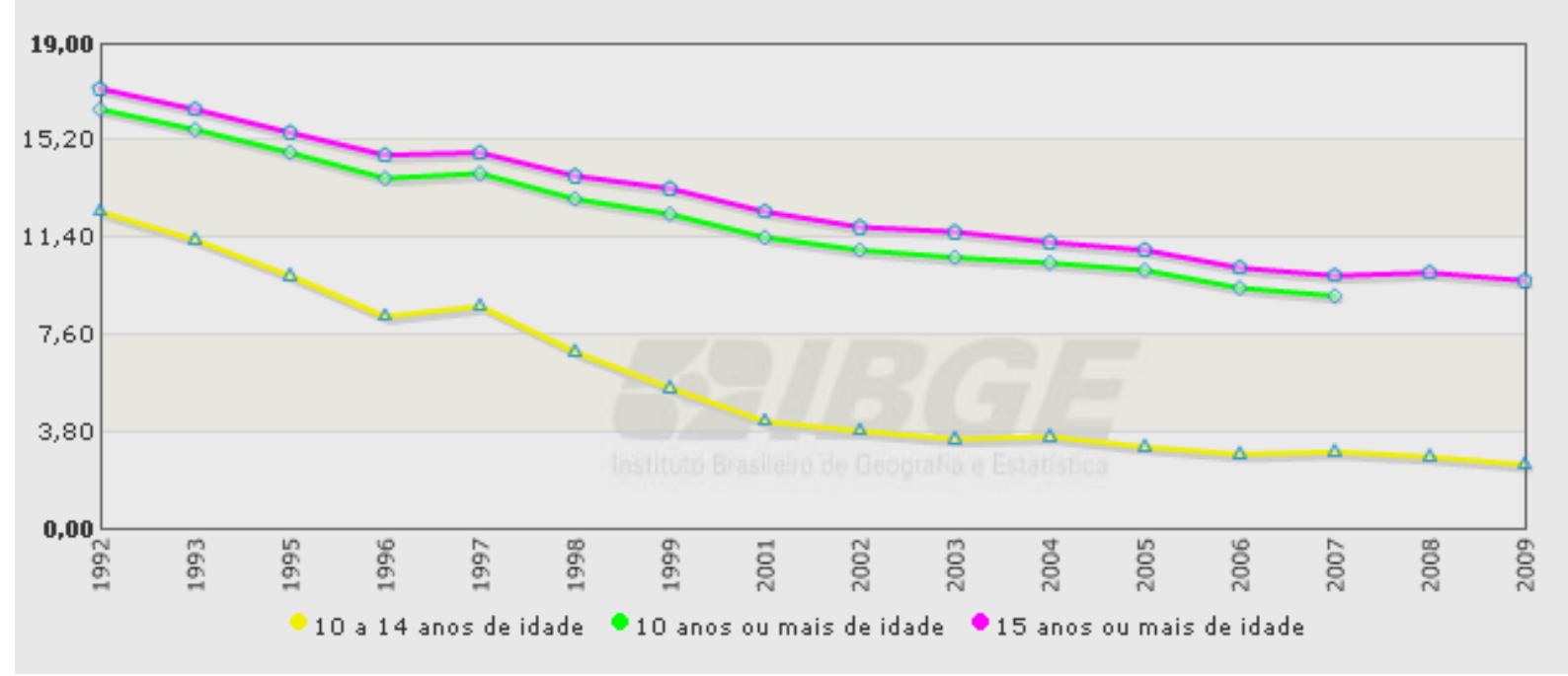

Taxa de aprovação, reprovação e abandono - Ensino Fundamental ${ }^{16}$.

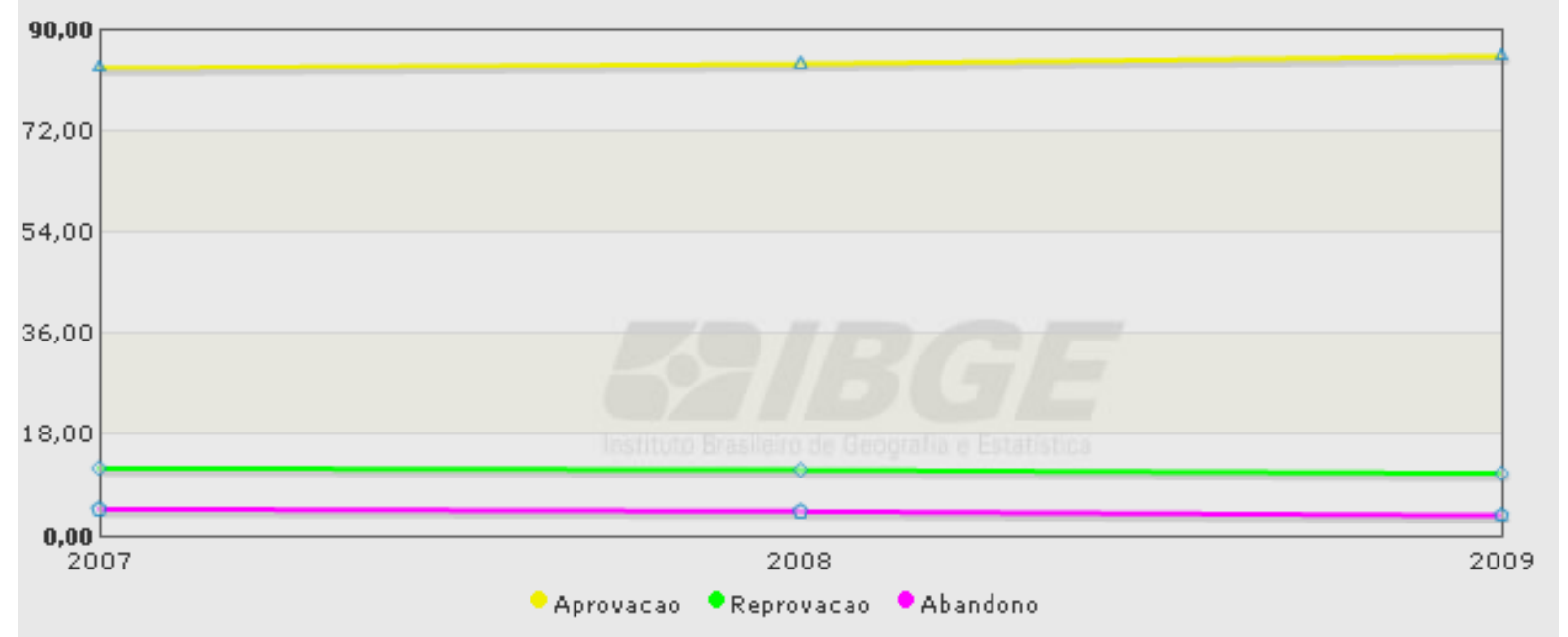

\footnotetext{
${ }^{15}$ Fonte: http://seriesestatisticas.ibge.gov.br/series.aspx?vcodigo=PD171\&t=taxa-de-analfabetismo-por-grupos-de-idade\#P1 - Acesso em 20 de maio de 2011.

${ }^{16}$ Fonte: http://seriesestatisticas.ibge.gov.br/series.aspx?vcodigo=M101\&t=taxa-de-aprovacao-reprovacao-e-abandono-ensinofundamental-serie-nova - Acesso em 20 de maio de 2011.
} 


\section{CONSIDERAÇÕES FINAIS}

Considerando a Política de Educação é possível concluir que no período de 1954 a 1964 não há efetivação grandes marcos para 0 desenvolvimento da educação no Brasil. A conquista mais evidente é a concretização da Lei de Diretrizes e Bases da Educação em 1961, que, por sinal, também não contempla todas as camadas sociais da população brasileira, tendo em vista que nem sempre a lei consegue mudar de forma imediata a realidade. Organizações mais progressistas, por exemplo, criam uma expectativa sobre a LBD, no sentido de ampliar o atendimento das necessidades das classes populares, o que não ocorre. As conferências nacionais, o levantamento de bandeiras, as manifestações e revoluções que ocorrem de 1954 ao início da ditadura militar são úteis no intuito da fundação de universidades públicas e de campanhas de alfabetização, mas ressalta que muitas ações efetivadas pelo poder público ocorrem apenas para contentar os revolucionários e apartar futuras reivindicações. O foco dos dirigentes políticos da época está voltado para a economia, os meios de produção, a construção de Brasília e não para a educação da população brasileira.

\section{REFERENCIAS}

AFFONSO, A. João Goulart: Presidente do povo. Brasília: Centro de documentação e informação coordenação de publicações, 1997. 19p.

BEISIEGEL, C. R. Política e educação popular: A teoria e a prática de Paulo Freire no Brasil. São Paulo: Ática, 1992. 304p.

BOJUNGA, C. JK: o artista do impossível. São Paulo: Objetiva, 2001. 800p.

BRAGA, J.C; PAULA, S. G.. Saúde e Previdência: Estudos de Política Social. São Paulo: Hucitec, 1986. 224p.

COHEN, M. Juscelino Kubitschek: o presidente bossa nova. São Paulo: Globo, 2005. 311p.
CUNHA, L. A. Educação e desenvolvimento social no Brasil. 9.ed. Rio de Janeiro: Francisco Alves, 1980. 291p.

CURY, C. R. J.. Ideologia e educação brasileira. 4.ed. São Paulo: Cortez, 1988. 201p.

MINDLIN, B. Planejamento no Brasil. 5. ed. São Paulo: Perspectiva, 2001.

TORO, J. B.; WERNECK, N. M. D.. Mobilização Social: um modo de construir a democracia e a participação. Belo Horizonte: Autentica, 2007. 104p.

TORO, J. B. A construção do público: cidadania, democracia e participação. Rio de Janeiro: Senac Rio, 2005. 112p.

http://seriesestatisticas.ibge.gov.br/

Acesso em:20 maio 2011.

http://momidi.com.br/meb - Acesso em: 02 Maio 2007.

http://www.adufu.org.br/Reforma\%20universitaria/ Exposi\%20o de motivos.htm - Acesso em: 02 Maio 2007.

http://www.anpuh.uepg.br/xxiiisimposio/anais/textos/K\%C3\%81TIA\%20CILENE \%20DA\%20COSTA.pdf - Acesso em: 02 Maio 2007.

http://www.cpdoc,fgv.br/ Acesso em: 14 de Jun. de 2007.2 http://elegis.bvs.br/leisref/public/search.php?\&lang=pt\&\& words $=($ Centro $\% 24+$ and + Sa\%FAde) + or+(posto $\%$ 24+and+saude\%24)\&label=Postos\%20de\%20sa \%C3\%BAde. Acesso em: 03 Julho 2007.

http://www.geocities.com/Athens/Parthenon/8007I pres.html. Acesso em: 02 Maio 2007.

http://www.histedbr.fae.unicamp.br/navegando/arti gos frames/artigo 064.html - Acesso em: 02 Maio 2007.

http://www.histedbr.fae.unicamp.br/navegando/pe riodo nacional desenvolvimentista arquivos.html - Acesso em: 02 Maio 2007.

http://internatorural.medicina.ufmg.br/saude no b rasil.pdf Acesso em: 03/ jul. 2007.

http://www.klepsidra.net/klepsidra13/estada04.ht m - Acesso em: 02 Maio 2007.

http://www.pedagogiaemfoco.pro.br/heb09.htm Acesso em:02 Maio 2007.

http://www.prossiga.br/anisioteixeira/fran/livro4/ch ama cap11.html Acesso em: 02 Maio 2007. 
http://pt.wikipedia.org/wiki/Lei de Diretrizes e B

ases da Educa\%C3\%A7\%C3\%A30 - Acesso

em: 02 Maio 2007. 